Revista de Ciencias Sociales - Número 67 (2015) - Páginas 13-48

Ordenamiento jurídico y decisiones judiciales: aproximaciones...

\title{
ORDENAMIENTO JURÍDICO Y DECISIONES JUDICIALES: APROXIMACIONES A PARTIR DE LA DICOTOMÍA LINGÜÍSTICA DE SISTEMA Y ACTOS INDIVIDUALES
}

\author{
LEGAL SYSTEM AND JUDICIAL DECISIONS: \\ APPROACHES FROM THE LINGUISTIC \\ DICHOTOMY BETWEEN SYSTEM \\ AND ACTS INDIVIDUAL
}

HELGA MARÍA LELL*

Universidad Nacional de La Pampa (Argentina)

hlell@ius.austral.edu.ar

\section{Resumen}

Este artículo pretende trazar un paralelismo entre algunas explicaciones brindadas por la Lingüística respecto de su objeto y cómo funcionarían ellas en el campo jurídico a partir del eje conceptual sistema/actos individuales. De esta manera, el objetivo principal es desarrollar la comparación entre las dicotomías ordenamiento jurídico/decisiones judiciales y sistema/habla. Para

* Especialista y Maestranda en Estudios Sociales y Culturales (FCH, Universidad Nacional de La Pampa). Doctoranda en Derecho (FD, Universidad Austral). Becaria interna del CONICET. Centro de Investigaciones en Ciencias Jurídicas (FCEyJ, Universidad Nacional de La Pampa). Docente auxiliar en Derecho Político y Filosofía del Derecho. Santa Rosa, La Pampa (Argentina). Artículo recibido el 14 de junio de 2015 y aceptado el 30 de noviembre de 2015.

Revista de Ciencias Sociales - Número 67 (2015) - Universidad de Valparáíso - ISSN 0716-7725-Valparáiso, Chile 
ello se recurre a la teoría saussureana y a las críticas efectuadas por Coseriu y Bajtín. Finalmente, se proponen tres reformulaciones en el Derecho.

\section{Palabras clave}

Ordenamiento jurídico; decisiones judiciales; Lingüística; dicotomía sistema/actos.

\section{Abstract}

This article aims to make a parallelism between some explanations provided by the Lingüistics for its study object and how they might work in the legal field, grounded on the basis of the conceptual axis system/individual acts. According to this, the main goal is to make a contrast between the dichotomies of normative system/judicial decisions and langue/parole. To do so, Saussure's theory will be the main resource. Also I will use Coseriu and Bajtin's critics to the saussurean ideas. Finally, three reformulations for legal theory are suggested.

\section{Keywords} dichotomy.

Normative system; judicial decisions; Lingüistics; system/acts

\section{Introducción $^{1}$}

La Lingüística ha encontrado en la dicotomía lengua/habla, a partir de Saussure, la carta fundacional y certera (más allá de algunas discrepancias) en su carácter de ciencia. Por su parte, la disciplina jurídica, aún continúa enfrentando críticas y embates respecto de su cientificidad por diferentes motivos, usualmente focalizados en

1. Este artículo es una versión ampliada de la ponencia "Paralelismos y aproximaciones entre la Lingüística y el Derecho en torno a la dicotomía sistema/ acto", presentada por la suscripta en la mesa temática "Discurso jurídico e interdisciplina” de las VII Jornadas Internacionales de Investigación en Filología y Lingüística, realizadas en La Plata, Argentina, entre el 21 y el 24 de abril de 2015. Organizadas por la Facultad de Humanidades y Ciencias de la Educación y la Asociación de Lingüística y Filología de América Latina.

Facultad de Derecho y Ciencias Sociales - Universidad de Valparaíso - Chile 
indeterminaciones ontológicas. Precisamente, en este trabajo, desde la perspectiva del Derecho, el objetivo central es desarrollar algunos aspectos de la dicotomía sistema/acto que subyace como base de aquella ya mencionada en la Lingüística y a otra propia del ámbito del Derecho: ordenamiento jurídico/decisiones judiciales, a fin de explicitar un núcleo de coincidencias entre ambas disciplinas. Ello, con la creencia de que, a partir de los desarrollos de la Lingüística, se pueden reconocer fenómenos y construir categorías explicativas para la disciplina jurídica. En el ámbito jurídico aún no se ha logrado conciliar la existencia de estos dos extremos, uno general o sistémico, perdurable en el tiempo, y otro individual, concreto y en constante devenir, de manera que puedan comprenderse como componentes igualmente relevantes de un mismo objeto de estudio. Ello ha conllevado al descarte de uno de los dos polos en desmedro del otro y a la negación de la riqueza gnoseológica y fáctica del descartado.

En particular, para acortar el marco teórico de la Lingüística, se trabajará con la postura saussureana como base y luego con las críticas de Coseriu y Bajtín.

\section{Problema de la Ciencia del Derecho en torno al ordenamiento jurídico y las decisiones judiciales}

La concepción de la Ciencia del Derecho como aquella que se aboca al estudio de la normatividad jurídica acarrea un problema: el de definir cuál de entre al menos dos analogados aborda, si el ordenamiento jurídico o las decisiones judiciales.

Esta cuestión convoca a una reflexión conexa respecto de cuál es la relación (siempre y cuando se acepte que hay algún vínculo) entre ambos extremos. Usualmente, uno de estos polos es relegado a un segundo plano en dependencia con el restante. Al respecto, pueden darse dos opciones extremas: a) o bien se dice que las decisiones judiciales no son más que una mera repetición individualizada de las normas jurídicas generales, con lo cual se niega toda su riqueza y se resta relevancia a la labor judicial; b) o bien se cree que el ordenamiento jurídico no existe plenamente sino a través de su manifestación en las decisiones judiciales, lo que transforma al sistema en un conjunto de enunciados superfluos o meros y posibles auxiliares del razonamiento judicial.

Revista de Ciencias Sociales - Número 67 (2015) - Universidad de Valparáíso - ISSN 0716-7725-Valparaíso, Chile 
De acuerdo con lo dicho, el problema puede ser definido en los siguientes términos: la Ciencia del Derecho no ha logrado comprender satisfactoriamente su objeto como un todo que integra tanto el ordenamiento jurídico como las decisiones judiciales o que pueda explicar en forma conjunta y congeniar los roles que ocupa el sistema de normas jurídicas generales en la vida del Derecho y la riqueza de las decisiones judiciales en el plano más concreto y práctico.

Esta enunciación del problema pone de manifiesto la cuestión respecto de cuál es el rol que cumple el saber jurídico práctico y los operadores que lo ponen en marcha en relación con las normas jurídicas generales y el ordenamiento jurídico que ellas conforman, esto es, si solo deben realizar una deducción lógica creadora de normas jurídicas individuales que nada agreguen a la vida del Derecho, o si tienen una función protagónica en la atribución de sentidos y en la concreción de un reparto aun cuando su actuación se enmarque en los preceptos normativos generales.

Al describirse este problema, se ha hecho mención a distintas cuestiones que concurren a su generación. A efectos de explicitarlas, puede decirse que:

1. Existen al menos dos extremos diferentes que son articulaciones del reparto: el ordenamiento jurídico, por un lado, y las decisiones judiciales, por el otro;

2. ambas existen y constituyen realidades independientes entre sí;

3. aún no existe consenso respecto de cuál de estos extremos es el verdadero objeto de la Ciencia del Derecho, es decir, si alguno tiene una relevancia preponderante, y, en tal caso, cuál;

4. toda decisión a favor de uno de estos extremos relega al restante a un segundo plano y prácticamente lo subsume en el selecto;

5. resulta un desafío epistemológico la consideración del ordenamiento jurídico, por un lado, y de las decisiones judiciales, por el otro, como objetos disciplinares en forma simultánea y en un pie de igualdad que se retroalimentan y complementan.

En cuanto a la idea del sistema de normas, como señala Douglas Price, no existe uniformidad respecto de este concepto aplicado al

Facultad de Derecho y Ciencias Sociales - Universidad de Valparaíso - Chile 
Derecho. Así, la distinción principal sigue siendo la confusión entre conceptos de "sistema": o bien el sistema como un conjunto de enunciados, es decir, como aparato lógico conceptual (acepción usual en la dogmática y en la teoría general del Derecho), o bien como sistema social, con las diferentes comprensiones que de tal expresión se han realizado en la Sociología y en la Psicología².

Una enumeración no exhaustiva de los distintos usos que ha adquirido el término de sistema en el campo jurídico es realizada por Barberis, quien señala las siguientes: 1) como sistematización extrínseca del Derecho que se obtenía reduciendo las normas a unos principios muy generales (acepción propia del iusracionalismo del siglo XVIII); 2) como el único orden intrínseco del Derecho y como el primero en poner en conexión los institutos jurídicos surgidos del comportamiento social mismo, sentido propio de la pandectística alemana del siglo XIX; 3) como una organización institucional que se sirve de normas pero que no se reduce a ellas (acepción atribuida por las teorías institucionalistas, especialmente a partir de Santi Romano); 4) como un orden que regula su propia creación, esto es un ordenamiento dinámico caracterizado por el hecho de autorregular su propia producción y aplicación, sentido adoptado por Kelsen; 5) como subsistema social, caracterizado por ser fáctico; acepción propia de la Sociología del Derecho3.

Por otro lado, el aporte de Alchourrón y Bulygin (en sus trabajos conjuntos e individuales) es insoslayable en cuanto se han ocupado de

2. Cfr. DOUGLAS PRICE, Jorge Eduardo. La decisión judicial. Santa Fe: Rubinzal-Culzoni, 2012, p. 217.

3. Cfr. BARBERIS, Mauro. "Estructura y dinámica de los sistemas jurídicos". Doxa. Cuadernos de Filosofía del Derecho. N²0, 1997. Alicante: Universidad de Alicante. Cabe destacar que dentro de este último grupo, existen diversas investigaciones que han seguido, principalmente, los desarrollos de la teoría general de los sistemas de Luhmann. Para ampliar, ver: LUHMANN, Niklas. Sistema jurídico y dogmática jurídica. Madrid: Centro de Estudios Constitucionales, 1983; DE GIORGI, Raffaele. Ciencia del Derecho y legitimación. México: Universidad Iberoamericana, 1998; y DOUGLAS PRICE, Jorge Eduardo. "¿Qué sistema? La idea de "sistema jurídico" y una "confusión” epistemológica”. Ideas \& Derecho. N 8, año 2012. Buenos Aires: Asociación Argentina de Filosofía del Derecho, pp. 53-74.

Revista de Ciencias Sociales - Número 67 (2015) - Universidad de Valparáíso - ISSN 0716-7725-Valparaíso, Chile 
las normas como enunciados normativos y han focalizado su atención en las normas como integrantes de los sistemas normativos desde un enfoque lógico. Parten estos autores del hecho de que la Teoría Pura del Derecho ha revelado a las normas jurídicas como estructuras lógicas que imputan una sanción a un antecedente lógico. De esta manera, las normas jurídicas que no acarrean sanciones quedan relegadas a un segundo plano y su juridicidad depende de las normas primarias o independientes. Esta concepción kelseniana ha sido criticada y ampliamente superada. Al partir de esta postura, Alchourrón y Bulygin sostienen que, para la teoría monista, las normas jurídicas responden a un esquema uniforme por lo que la Ciencia del Derecho debería poder dar cuenta de la diversidad de enunciados que conforman los cuerpos legales. Pero no todos los enunciados que figuran en tales textos son normativos en el sentido de expresar normas de conducta con prescripción de acciones, ni todos los que son normativos imponen sanciones. La concepción kelseniana salvaría este escollo al sostener que las normas no independientes son jurídicas gracias a su conexión esencial con las normas sancionadoras. Por lo tanto, señalan los autores bajo análisis, que la norma jurídica se define a nivel sistémico, o sea, del ordenamiento jurídico. De esta manera, el ordenamiento jurídico se conforma con diversos tipos de enunciados prescriptivos, algunos de los cuales deben ser sancionadores. La norma jurídica es toda norma integrante de un sistema jurídico. Cabe aclarar que, entre los enunciados que componen el sistema, se encuentran enunciados jurídicos no normativos como los que establecen definiciones o postulados de significación, y las llamadas 'normas derogatorias'.

Ahora bien, tras manifestar esta complejidad del uso del término "sistema jurídico", cabe otra pregunta de no menor relevancia: ¿̇qué son las normas jurídicas generales? Una primera aproximación a la definición de estas deriva en que son aquellas prescripciones destinadas

4. $\mathrm{Al}$ respecto puede consultarse ALCHOURRÓN, Carlos E. y BULYGIN, Eugenio. Introducción a la metodología de las ciencias jurídicas y sociales. $2^{\circ}$ reimpresión. Buenos Aires: Astrea, 1975/1993; y BULYGIN, Eugenio. "Sentencia judicial y creación de derecho”. En: Alchourrón, Carlos y Bulygin, Eugenio. Análisis lógico y Derecho. Madrid: Centro de Estudios Constitucionales, 1992.

Facultad de Derecho y Ciencias Sociales - Universidad de Valparaíso - Chile 
a regir un número indeterminado de actos a lo largo del tiempo de su vigencia y que no se encuentran circunscriptas para producir efectos en un solo caso o conjunto de casos limitados, establecido/s, pensado/s o determinado/s en forma apriorística. De esta forma, las normas generales son el fundamento de las normas jurídicas individuales elaboradas por los jueces ante su deber de decidir conforme al ordenamiento jurídico y frente a hechos concretos. Las normas jurídicas individuales, según esta concepción, son aquellas que contemplan un caso particular y solo a él le otorgan sentido a la luz del marco normativo genérico y de otras fuentes de juridicidad.

Dentro de esta línea, por ejemplo, Moreso y Vilajosana ${ }^{5}$ explican que los casos genéricos se caracterizan por una propiedad que permite identificar una clase de personas, objetos, acciones o estados de cosas mientras que, por su lado, los casos individuales existen en un tiempo y espacio determinados (son personas, objetos, acciones o estados de cosas concretos). Para estos autores, la relación que existe entre ambos extremos es la misma que existe entre la blancura y un papel blanco.

Por su parte, García Máynez ${ }^{6}$ contrasta aquellas normas que obligan o facultan a todos los comprometidos dentro de una clase contemplada en el concepto de la disposición normativa con aquellas que solo se aplican a uno o varios miembros, individualmente determinados, de la clase designada por el concepto de los preceptos generales.

$\mathrm{Al}$ respecto, también Hernández Marín ${ }^{7}$ señala que las normas jurídicas generales son enunciados que se refieren a un número ilimitado de individuos y las individuales son enunciados que se refieren a uno o más individuos determinados. De esta forma, sobre todo enunciado individual cabe formular un enunciado general que tenga el mismo

5. Cfr. MORESO, Juan José y VILAJOSANA, Josep María. Introducción a la teoría del derecho. Madrid: Marcial Pons, 2004, pp. 73-74.

6. Cfr. GARCÍA MÁYNEZ, Eduardo. Introducción al Estudio del Derecho. $51^{\circ}$ ed. México: Ed. Porrúa, p. 82.

7. Cfr. HERNÁNDEZ MARÍN, Rafael. Introducción a la teoría de la norma jurídica. Madrid: Marcial Pons, 1998, pp. 197-199.

Revista de Ciencias Sociales - Número 67 (2015) - Universidad de Valparáíso - ISSN 0716-7725-Valparaíso, Chile 
sentido. Así, ambos enunciados son casi sinónimos y equivalentes en significado.

Sin embargo, la última afirmación es dudosa. Si se opta por erigir al ordenamiento jurídico en el objeto principal y subsumir a las decisiones judiciales a una mera repetición y aplicación de la primera con las determinaciones del caso concreto, nuevas complejidades se plantean, especialmente porque no pueden comprenderse satisfactoriamente aquellos casos en los que una decisión judicial discrepa con el sentido consolidado o atribuido a la norma general hasta cierta instancia temporal, ni tampoco aquellos casos en los que la sentencia brinda una solución que se aparta del marco jerárquicamente superior o lo enriquece de alguna manera. Por ejemplo, puede ocurrir, que en una sentencia un juez determine conceptos, solucione problemas propios del lenguaje como la ambigüedad, la vaguedad o la textura abierta de los términos con los que una norma ha sido elaborada, complete lagunas del ordenamiento jurídico, cree excepciones no contempladas en las normas jurídicas generales porque la autoridad normativa no ha podido prever el caso o que recurra a la equidad en pos de corregir un resultado que eventualmente sería injusto a la luz de las circunstancias particulares del caso concreto ${ }^{8}$.

En contraposición con lo comentado, si se concibe a las decisiones judiciales como el objeto disciplinar protagónico, las normas jurídicas generales resultan relegadas al papel de auxiliares que inspiran el contenido de las jerárquicamente inferiores, sin ser vinculantes. En este

8. Este tema ha sido trabajado por la tesista. En: Lell, Helga María.

"Hermenéutica judicial y discurso judicial: la retórica como instrumento para la aceptación de sentidos normativos novedosos". Ponencia expuesta en el II Coloquio Nacional de Retórica "Los códigos persuasivos: historia y presente" y el I Congreso Internacional de Retórica e Interdisciplina, organizado por la Asociación Argentina de Retórica (AAR) y llevado a cabo en Mendoza, Argentina, los días 21, 22 y 23 de marzo de 2013 y Lell, Helga María. "La Equidad: un criterio de interpretación legal". Trabajo presentado en la mesa redonda de Ciencias Jurídicas: "A Antiguidade no Direito” en el XVIII Congresso Nacional de Estudos Clássicos. Antiguidade: Performance e Recepção, llevado a cabo en la Universidad Federal de Río de Janeiro con el auspicio de la Sociedad Brasilera de Estudios Clásicos, en Río de Janeiro, Brasil, los días 17 al 21 de octubre de 2011; por lo que, para ampliar, allí se remite.

Facultad de Derecho y Ciencias Sociales - Universidad de Valparaíso - Chile 
caso, la inferioridad jerárquica solo se determinaría en relación con la posición en la clásica ilustración del sistema normativo kelseniano de Merkel que presenta al ordenamiento jurídico como una pirámide con gradas escalonadas, y no por la existencia de una vinculatoriedad del contenido de las normas jurídicas de gradas superiores. Esto resuelve los problemas expuestos en los párrafos precedentes pero no logra dar cuenta de la relevancia real e innegable que tienen las normas jurídicas generales.

Esta postura, por ejemplo, se acerca al realismo jurídico norteamericano que propugna que el Derecho se compone de los precedentes judiciales y que la tarea del jurista implica la predicción acerca de cómo sentenciarán los jueces frente a ciertos casos. La actitud realista jurídica norteamericana afirma que los jueces o los órganos aplicadores sienten el Derecho cuando se enfrentan a un caso concreto $\mathrm{y}$, al interpretar los hechos, realizan un acto de creatividad personal tanto en cuanto al derecho legislado como a los principios surgidos de los precedentes ${ }^{9}$.

Pero también, en el marco de una postura no positivista o transpositivista ${ }^{10}$, Alexy señala que, conforme a una máxima restrictiva respecto de los problemas que conciernen a la filosofía del Derecho, preguntar acerca del estatus ontológico de las normas jurídicas es tan carente de importancia como para los geógrafos preguntarse acerca de la existencia real o imaginaria de una montaña en el África que han contemplado e identificado. Pero, indica el profesor de la Universidad

9. Cfr. CUETO RÚA, Julio César. "La jurisprudencia sociológica norteamericana”. En: Anuario de filosofía jurídica y social. Buenos Aires: Asociación Argentina de Derecho Comparado. Abeledo Perrot, 1981, pp. 59-73 y Álvarez Gardiol, Ariel. Manual de filosofía del derecho. Buenos Aires: Editorial Astrea, 1979, pp. 171-173.

10. Esta denominación de "transpositivista" es tomada de Massini Correas quien la utiliza para denominar así a todas las posiciones o doctrinas filosóficas que no aceptan la tesis central del positivismo jurídico en sentido estricto acerca de la reducción de todo lo jurídico al derecho positivo. Dentro de este marco incluye a las posturas jusnaturalistas en sentido estricto y a las constructivistas. Cfr. MASSINI CORREAS, Carlos Ignacio. El derecho natural y sus dimensiones actuales. Buenos Aires: Editorial Ábaco, 1999, pp. 19-23.

Revista de Ciencias Sociales - Número 67 (2015) - Universidad de Valparáíso - ISSN 0716-7725-Valparáiso, Chile 
de Kiel, la respuesta a la pregunta sobre las normas, tiene una significación distinta para los juristas que aquella que se presentó para los geógrafos en tanto determina la respuesta a otro interrogante sobre el quehacer jurídico. Este es si las normas jurídicas pueden ser concebidas como elementos de un sistema de inferencias y, así, como punto de partida de argumentos, o si ellas son solo elementos que integran una red causal. A su vez, esto último, tiene una incidencia directa respecto de considerar si el razonamiento práctico orientado hacia la corrección tiene o no algún sentido ${ }^{11}$.

Por otro lado, Bernal entiende por decisión judicial el acto por el cual, un juez soluciona un caso concreto, de acuerdo al Derecho, en ejercicio de la autoridad que el Estado y el sistema jurídico le confieren. "En una decisión judicial el juez dice algo acerca del Derecho, de los hechos del caso y de las consecuencias que el sistema jurídico le imputa a las partes" 12 .

Hasta aquí se han expuesto tan sólo algunas escasas posiciones en relación al tema que no agotan las opiniones que sobre él se han vertido. Lo hecho aquí pretende tan sólo brindar una pequeña muestra acerca de cómo se polarizan las posiciones en torno al lugar que ocupan las normas jurídicas generales y las decisiones judiciales en el proceso de interpretación a los efectos de realizar una presentación del problema. Como puede notarse, ninguna de estas opciones logra poner en un pie de igualdad ambos extremos normativos y las aproximaciones que se realizan no resultan plenamente satisfactorias. El problema, entonces, es el de congeniar un plano general con el particular sin negar las riquezas propias de cada uno y sin excluir uno de los dos extremos. También, es necesario definir qué roles ontológico y epistemológico

11. Cfr. ALEXY, Robert. El concepto y la naturaleza del derecho. Carlos Bernal Pulido (trad.). Madrid/Barcelona/Buenos Aires: Marcial Pons, 2008.

12. BERNAL, Carlos L. "Un análisis de las decisiones judiciales con base en la teoría de los actos de habla”. European Journal of legal studies. Autumn/Winter. 2007. Volume 1. Issue 2, p. 1. Esta versión es una traducción realizada por el autor con la colaboración de Jorge Luis Fabra Zamora y Carolina Esther Guzmán Buelvas. El original ("A Speech Act Analysis of Judicial Decisions") en idioma inglés puede ser consultado en el mismo número, volumen y revista.

Facultad de Derecho y Ciencias Sociales - Universidad de Valparaíso - Chile 
ocupa el ordenamiento jurídico como plano abstracto y si es posible desarrollar algún tipo de conocimiento genérico a partir de las decisiones judiciales, siempre particulares y diferentes unas de otras y, además, destinadas a regir sobre un caso concreto. La diferencia radica en que, aun cuando tengan exactamente el mismo sentido, constituyen decisiones particulares, destinadas a regir un caso concreto. Por lo tanto, habrá tantas decisiones judiciales como casos se hayan resuelto y tantas particularidades como decisiones judiciales haya.

En estos términos es que se plantea el problema de la Ciencia del Derecho para abordar el eje sistema/actos individuales. La lingüística ha atravesado un problema semejante y, a partir de Saussure, si bien han surgido múltiples respuestas, la cientificidad de esta disciplina se encuentra aceptada con base en la distinción entre lengua y habla.

\section{El sistema y los actos individuales en la visión saussureana}

Para Saussure, una vez deslindada la lengua del lenguaje, es necesario analizar su relación con el habla. Así, el primer reto que afronta el lingüista ginebrino en relación con su disciplina es la necesidad de hallar un objeto concreto, delimitado, empírico y asequible. En este marco es que plantea la dicotomía lengua/habla que, en términos más genéricos, se identifica con la antinomia sistema/actos individuales. Para llegar a ella, el lingüista ginebrino recorta, dentro del vasto ente que es el lenguaje ${ }^{13}$, a la lengua. Si bien esto no implica la negación de algún tipo de aseveración acerca de la esencia del lenguaje, al menos logra solucionar la necesidad de tomar una postura filosófica acerca de su definición ontológica mediante una elusión (no definir el ente) y una alusión (señalar que es una facultad de articular).

De la misma manera, la búsqueda de un objeto disciplinar en la Ciencia del Derecho responde a una necesidad semejante a aquella desde la que nace la dicotomía lengua/habla. Así como Saussure

13. Cabe recordar que el lingüista suizo caracteriza al lenguaje como un objeto heteróclito, a caballo en varios dominios como el físico y el psíquico, y repleto de paradojas: es social e individual a la vez, es estático y mutable al mismo tiempo, entre otras características.

Revista de Ciencias Sociales - Número 67 (2015) - Universidad de Valparáíso - ISSN 0716-7725-Valparaíso, Chile 
Helga María Lell

propone a la lengua como el objeto de estudio disciplinar, en la Ciencia del Derecho, en paralelo con la visión saussureana, las normas jurídicas generales y el ordenamiento jurídico que ellas conforman ocupan un lugar protagónico. En contraste con ello, a las decisiones judiciales y la relación que ellas guardan con las normas jurídicas generales y el ordenamiento jurídico, les pertenece un lugar equivalente al del habla en la Lingüística saussureana ${ }^{14}$.

14. Existe un grupo de investigación que se ha dedicado a analizar, de manera semejante a la aquí propuesta, las equivalencias entre el Derecho y los aportes estructuralistas. A raíz de ello, se han aplicado muchas de las categorías analíticas de lingüistas a la disciplina jurídica, entre ellas, la de Saussure (aunque no sea un estructuralista en el sentido estricto). No obstante lo dicho, la concepción de la que parte este grupo posee una visión distinta a la aquí propuesta en tanto al habla equipara tanto el ordenamiento jurídico como los actos de realización del Derecho. Señala Hernández Gil, a cargo de este grupo, que una primera consideración parece descubrir con facilidad los correlatos jurídicos del lenguaje, lengua y habla. Lo serían, respectivamente: el "Derecho" — equivalente del lenguaje- como el concepto global susceptible de comprender todas las manifestaciones de una organización vinculante del comportamiento intersubjetivo; el "ordenamiento jurídico" — equivalente de la lengua - constituido por el sistema jurídico vigente en una determinada comunidad social; y la "realización del derecho" — equivalente del habla — que comprendería la aplicación del sistema representado por el ordenamiento jurídico. No obstante, luego, el autor señala que, entre la lengua y el ordenamiento jurídico configurado como conjunto de normas, son muy marcadas las diferencias. "Por el lenguaje se logra la inteligencia, pero no de un modo general y universal, sino a través de cada lengua; por el derecho se alcanza la convivencia, pro enmarcada en ordenamientos o regímenes jurídicos determinados. Ahora bien, la lengua conserva una espontaneidad y densidad sociales que en el derecho decrecen o se transfiguran a través del hecho cierto de su progresiva estatalización. Mientras la lengua sigue siendo fruto de consensos sociales imperceptibles, sin una promulgación y una derogación impuestas, el derecho, que en sus fases primarias tuvo manifestaciones análogas, ha experimentado un proceso de tecnificación y formulación creciente a expensas del Estado, rector del "orden jurídico" y formulador de los ordenamientos jurídicos".

Luego, propone que las diferencias observadas entre el significado de la lengua y el del ordenamiento jurídico, así como algunas características intrínsecamente correspondientes a él, tienen más bien su equivalencia en el habla en el sentido saussureano. Esto acarrea como consecuencia que el ordenamiento jurídico y la realización del derecho se aproximen y, por ello, para este grupo de investigadores el Derecho se realiza en dos instancias: una cuando recibe formulación normativa y otra cuando se manifiesta a través de fenómenos concretos de actuación.

Facultad de Derecho y Ciencias Sociales - Universidad de Valparaíso - Chile 
Entonces, en principio, la idea comentada de la Lingüística tiene un impacto en la visión de la disciplina jurídica. A efectos de considerarla en paralelo con su par lingüística desde los desarrollos saussureanos, se la debe pensar en dos planos de un trágico antagonismo ${ }^{15}$. Por un lado, en el ámbito lingüístico se encuentran: 1) la lengua, es decir, el sistema, y 2) el habla, o sea, los actos lingüísticos; y, por el otro, en el campo jurídico, se pueden observar: 1) las normas jurídicas generales que, a partir de sus relaciones mutuas, forman un sistema, un ordenamiento jurídico a la luz del cual presentan un sentido, y 2) las decisiones judiciales o actos individuales brindados frente a un caso concreto.

Ahora bien, señalado el inicio del paralelismo que se realiza entre ambas disciplinas, resulta necesario aclarar los términos propios de la Lingüística. En virtud de la relevancia conferida a la lengua como modelo del sistema que goza de aceptación científica en su calidad de objeto, resulta prioritario comenzar por su definición.

Bajo la influencia del interés positivista por deslindar las ciencias y dotarlas de un objeto fáctico y un método de estudio adecuado, Saussure recortó dentro de aquel incierto universo que para él es el lenguaje lo que él define como el objeto de la Lingüística, esto es, la lengua ${ }^{16}$. Dice el maestro ginebrino:

En cuanto al equivalente de la lengua, se encuentra en la base del ordenamiento jurídico. Es algo presupuesto por este y que le hace posible. El ordenamiento es la versión o las versiones de un sistema subyacente a expensas del cual se elaboran las formulaciones normativas. Cfr. HERNÁNDEZ GIL, Antonio, NÚÑEZ LADEVÉZE, Luis, SOBRADO CHÁVEZ, Juan José, MESA MENGÍBAR, Andrés, PECES Y MORATE, Jesús Ernesto y PÉREZ DE GRACIA, José Antonio. Estructuralismo y Derecho. Madrid: Editorial Alianza, 1973, pp. 43-49. La cita textual pertenece a las págs. 43-44.

15. El antagonismo se plantea a partir de la relación dicotómica desde la cual Saussure define los extremos y que aquí se intenta exponer y revelar su traslado al Derecho. La caracterización como "trágico" se debe a la indiscutible relación entre el sistema y el acto, entre la lengua y el habla y entre el ordenamiento jurídico y las normas jurídicas generales que lo conforman, por un lado, y las decisiones judiciales, por el otro, relación que se da en un marco de tensión y que, aún a pesar de lo antagónico de los dos polos, cada uno de ellos necesita del otro inevitablemente.

16. Cfr. VITALE, Alejandra. El estudio de los signos. Peirce y Saussure. $1^{\circ}$ ed. $9^{\circ}$ reimp. Buenos, Aires: Eudeba, 2010, p. 70.

Revista de Ciencias Sociales - Número 67 (2015) - Universidad de Valparaíso - ISSN 0716-7725-Valparaíso, Chile 
Helga María Lell

A nuestro parecer, no hay más que una solución para todas estas dificultades: hay que colocarse desde el primer momento en el terreno de la lengua y tomarla como norma de todas las otras manifestaciones del lenguaje. En efecto, entre tantas cualidades, la lengua parece ser lo único susceptible de definición autónoma y es la que da un punto de apoyo satisfactorio para el espíritu ${ }^{17}$.

La lengua es una parte esencial del lenguaje, es el producto social de la facultad de este y un conjunto de convenciones necesarias por las cuales los individuos hacen ejercicio de dicha facultad ${ }^{18}$. O sea, para conocer el lenguaje o lo que pueda saberse de él, es necesario atravesar por la lengua y los límites del campo exploratorio de ella marcan las fronteras de lo cognoscible en torno al lenguaje ${ }^{19}$.

17. SAUSSURE, Ferdinand de. Curso de lingüística general. Publicado por Charles Bally y Albert Sechehaye con la colaboración de Albert Riedlinger. Amado Alonso (trad.). Buenos Aires: Losada, 1945, p. 51. La versión francesa dice: "Il n’y a, selon nous, qu'une solution à toutes ces difficultés: il faut se placer de prime abord sur le terrain de la langue et la prendre pour norme de toutes les autres manifestations du langage. En effet, parmi tant de dualités, la langue seule paraît être susceptible d'une définition autonome et fournit un point d'appui satisfaisant pour l'esprit". SAUSSURE, Ferdinand de. Cours de linguistique générale. Publié par Charles Bally et Albert Séchehaye avec la collaboration de Albert Riedlinger. Édition critique préparée par Tulio de Mauro. Paris: Éditions Payot \& Rivages, 1967, p. 25.

18. Cfr. SAUSSURE. Curso de..., p. 50.

19. Esto recuerda a la conocida frase de Wittgenstein: "5.6. Los límites de mi lenguaje significan los límites de mi mundo" ("Die Grenzen meiner Sprache bedeuten die Grenzen meiner Welt"), que tiene su correlato en el prólogo del Tractatus, donde señala que "El libro quiere, pues, trazar un límite al pensar o, más bien, no al pensar, sino a la expresión de los pensamientos: porque para trazar un límite al pensar tendríamos que poder pensar ambos lados de este límite (tendríamos, en suma, que pensar lo que no resulta pensable)” — “Das Buch will also dem Denken eine Grenze ziehen, oder vielmehr — nicht den Denken, sondern dem Ausdruck der Gedanken: Denn um dem Denken eine Grenze zu ziehen, müssten wir beide Seiten dieser Grenze denken können (wir müssten also denken können, was sich nicht denken lässt)"solo que, a la luz de las precisiones de la Lingüística, la lengua es el campo de reconocimiento del lenguaje. Cfr. WITTGENSTEIN, Ludwig. Tractatus lógicophilosophicus. Edición bilingüe. Jacobo Muñoz e Isidora Reguera (trad.). $1^{\circ}$ ed. $4^{\circ}$ reimp. Madrid: Alianza Ed., 1987/1993. Las citas textuales se encuentran en las páginas $143,142,11$ y 10 , respectivamente.

Facultad de Derecho y Ciencias Sociales - Universidad de Valparaíso - Chile 
La lengua constituye un orden y un principio de clasificación al punto tal que Saussure la presenta como la unidad del lenguaje. La preeminencia de la lengua se funda en que la facultad de articular se ejerce gracias a la ayuda del instrumento creado y suministrado por la colectividad $^{20}$.

La lengua revela el uso que se hace del lenguaje. Bajo la premisa de que la articulación implica la subdivisión de la cadena de significaciones en unidades significativas — valga la redundancia—, se puede decir que la lengua es el lenguaje articulado ${ }^{21}$ y su conformación es una tarea llevada a cabo por una colectividad en forma involuntaria ${ }^{22}$.

Entonces, lo clave en este punto es que la lengua es una manifestación lingüística que se muestra en una comunidad dada, en la cual se crea y se mantiene. Los individuos por sí solos no la modifican, no pueden realizar una ruptura lógica y abrupta en ella.

El sistema constituye la primera unidad analizable de aquello que se considera una esencia, desde una perspectiva que va de lo más abstracto a lo más concreto. Es un objeto concreto, delimitado, empírico y asequible. Esta idea le permitió a Saussure soslayar el expedirse respecto del ser del lenguaje como esencia y tomarlo simplemente como una facultad de articulación. De allí que el estudio de las articulaciones lingüísticas sea lo central para la Lingüística como ciencia.

Tras dejar de lado este plano heteróclito e indefinible en su totalidad y complejidad que es el lenguaje, Saussure plantea dos planos: a) uno social y esencial; este es la lengua que, en términos abstractos, es un sistema; y b) otro particular y contingente, el cual es el habla o el acto individual. El sistema es una primera articulación empírica de la esencia y por lo tanto el punto de inicio de los estudios científicos.

20. Cfr. SAUSSURE. Curso de ..., pp. 51-52.

21. La idea de la "subdivisión de la cadena de significaciones en unidades significativas" da a entender que el mundo de significaciones es un continuo indistinto hasta la instancia de la articulación del lenguaje. La subdivisión de la cadena debería darse en dos planos (los mismos que componen el signo lingüístico): en el del significante y en el del significado. Cfr. SAUSSURE. Curso de..., pp. 52-53.

22. Esta característica de "involuntaria" debe entenderse como "inconsciente" o "no intencional".

Revista de Ciencias Sociales - Número 67 (2015) - Universidad de Valparáíso - ISSN 0716-7725-Valparaíso, Chile 
Es esta idea la que se pretende retomar aquí en virtud del problema planteado en el campo del Derecho y la afirmación que convoca estos párrafos. Como puede observarse, tanto en la Lingüística tal como la concibió Saussure como en la disciplina jurídica existe un sistema de comprensión que enmarca los actos individuales. A su vez, estos últimos no constituyen un elemento esencial pero en forma involuntaria e inconsciente actúan sobre el sistema general, influyen sobre él y lo modifican.

El sistema constituye, paradójicamente, una articulación de una esencia y un conjunto de convenciones necesarias para que los sujetos puedan hacer uso particular de la esencia ${ }^{23}$. En forma paralela a lo que ocurre en la Lingüística, donde el sistema es la lengua y los actos individuales conforman el habla, en el ámbito de la Ciencia del Derecho, una articulación de la esencia jurídica la constituye el ordenamiento jurídico como sistema de normas jurídicas generales que estructuran de manera abstracta un reparto y que, a su vez, disponen las pautas mediante las cuales los jueces y los sujetos normativos puedan hacer uso de él. Asimismo, en cuanto a los actos individuales, las decisiones judiciales constituyen un uso contextualizado y concreto de aquel sistema normativo.

\section{La naturaleza social del sistema y particular de los actos individuales en la visión saussureana}

Otra afirmación que merece ser traída a colación desde la Lingüística saussureana apunta que la lengua es una construcción social

23. La paradoja radica en el hecho de que el sistema es al mismo tiempo articulación de una esencia y las convenciones para utilizar esa esencia, es decir, el problema se asemeja al famoso problema respecto de quién ha existido primero, si el huevo o la gallina. Si el sistema es una articulación, entonces, el lenguaje ya se encuentra articulado sin necesidad de la existencia previa de las convenciones para el uso por parte de los individuos. Esto quiere decir, que el lenguaje se ha articulado por sí mismo y las convenciones se han auto-creado. En realidad, para Saussure, es la comunidad la que en forma involuntaria y "masiva" crea estas convenciones. Pero dexisten actos de la comunidad inconscientes sin actos individuales? Si el sistema es el que provee las convenciones para que los sujetos puedan articular el lenguaje pero el sistema ya es una articulación, el rol de los individuos es, al menos, contingente puesto que la lengua crea sus propias reglas de uso.

Facultad de Derecho y Ciencias Sociales - Universidad de Valparaíso - Chile 
y que, al mismo tiempo, permite a la sociedad articular el lenguaje. El sistema, en estos términos, se plantea como una abstracción fuera del alcance del arbitrio de los individuos y radicada en la sociedad. Por su parte, el habla y los actos individuales se presentan como elementos pertenecientes solo a los sujetos hablantes o actuantes, respectivamente. En ellos no existe nada de social fuera de ser comprensibles a la luz de la lengua o el sistema. ¿Tiene sentido este panorama para explicar la naturaleza del ordenamiento jurídico y las normas jurídicas generales que lo componen, por un lado, y de las decisiones judiciales, por el otro?

La lengua existe en la colectividad, su naturaleza es social y no puede escindirse la masa hablante de su concepto ${ }^{24}$. Así, es común a todos y está situada fuera de la voluntad de cada uno de los depositarios ${ }^{25}$ del código lingüístico. El conjunto de los hábitos lingüísticos permite que un sujeto pueda comprender y hacerse comprender ${ }^{26}$. El habla es la adición de todo lo que cada sujeto integrante de una comunidad dice, de las combinaciones voluntarias que cada sujeto efectúa y por lo tanto es solo la suma de casos particulares. Para el lingüista suizo esto implica que en el habla no haya nada de colectivo y que estos actos sean individuales y momentáneos.

Dice Saussure: "Por todas estas razones sería quimérico reunir en un mismo punto de vista la lengua y el habla. El conjunto global del lenguaje es incognoscible porque no es homogéneo, mientras que la distinción y la subordinación propuestas lo aclaran todo" ${ }^{27}$. Esta frase

24. Precisamente Saussure combina la fuerza social con el factor temporal de otro capítulo. donde surge la noción del cambio lingüístico que es tema de tratamiento de

25. El término de "depositarios" se debe a que Saussure describe a la lengua como un conjunto de acuñaciones depositadas en cada cerebro y la compara con un diccionario cuyos ejemplares son repartidos entre los individuos.

26. Cfr. SAUSSURE. Curso de..., p. 144.

27. Ídem, p. 65. La versión francesa dice: "Pour toutes ces raisons, il serait chimérique de réunir sous un même point de vue la langue et la parole. Le tout global du langage est inconnaissable, parce qu'il n'est pas homogène, tandis que la distinction et la subordination proposées éclairent tout”. SAUSSURE. Cours de..., p. 38 .

Revista de Ciencias Sociales - Número 67 (2015) - Universidad de Valparáíso - ISSN 0716-7725-Valparaíso, Chile 
pone en relieve la importancia de distinguir los tres niveles: lenguaje, lengua y habla en la teoría de este lingüista ginebrino. De entre ellos, el primero no es susceptible de estudio empírico per se pues es el principio de los otros dos. Precisamente, es mediante la dicotomía lengua y habla que puede llegar a conocerse el lenguaje. La lengua es el grado más genérico de entre las manifestaciones del lenguaje en forma tangible y susceptible de estudio, de allí el interés del estructuralismo en esta noción como su base. La lengua radica en la comunidad y se asienta en ella en forma pasiva, nadie puede modificarla por sí solo a la par que hace inteligible el habla. El habla es la manifestación individual e implica el uso y las combinaciones que cada individuo realiza de la lengua. De esta manera asienta a la lengua en una instancia histórica pero también la mueve paulatinamente en el cambio.

En el campo del Derecho, es posible concebir al sistema jurídico como perteneciente a la colectividad y fuera del alcance de la voluntad de cada individuo. Es decir, en cuanto al sentido de las normas jurídicas generales, este constituye una suerte de "tesoro" depositado en las mentes de los sujetos o un promedio de conceptos asociados (en palabras de Saussure), con independencia de la interpretación individual de cada sujeto normativo o de cada juez decisor en particular.

En cuanto al plano de las decisiones judiciales, ellas son el producto de la interpretación y argumentación de un juez o un tribunal interviniente frente al caso concreto. La decisión resultante es puramente particular, emitida por un solo individuo, en un momento histórico concreto y frente a ciertos particulares sobre los cuales recaerán los efectos de la prescripción. La norma jurídica general y el ordenamiento jurídico cobran un sentido único e individual para el caso concreto.

Las normas jurídicas generales, al menos en lo que respecta a su sentido, existirían solo en la colectividad y escaparían a la mera voluntad particular y requerirían de una aceptación masiva. En cambio, las decisiones judiciales pueden conformar un conjunto pero tan sólo a partir de una simple sumatoria. Por lo tanto, no serían un concepto general sino tan sólo una pluralidad de actos individuales semejantes o con alguna coincidencia mediante.

Facultad de Derecho y Ciencias Sociales - Universidad de Valparaíso - Chile 
Ordenamiento jurídico y decisiones judiciales: aproximaciones...

\section{Las insuficiencias de la visión saussureana según Coseriu}

Asimismo, es interesante la confusión de distintos conceptos de lengua que Coseriu le atribuye a Saussure. El lingüista rumano acusa a su par suizo de considerar como equivalentes conceptos de la lengua que no lo son (ej. acervo lingüístico, aspecto social del lenguaje, sistema, sistema funcional $)^{28}$.

Así, Saussure utiliza el concepto de lengua en al menos tres sentidos distintos sin identificar él mismo que se trata de tres acepciones diferentes: 1) la lengua como una realidad psíquica que comprende significados e imágenes acústicas; 2) una realidad social, un producto o institución social que no se realiza en forma completa en ningún individuo, que no existe más que en la masa; y 3) una realidad sistemática y funcional, independiente de la parte psíquica y de su determinación social en que los signos distintos se corresponden a ideas distintas, es un código en el que solo es esencial la unión del sentido y de la imagen acústica. Estos tres conceptos presentan muchas coincidencias entre sí pero claramente no son idénticos y son construidos desde tres puntos de vista distintos ${ }^{29}$.

Además, si bien los tres conceptos coexisten y se presentan simultáneamente, Saussure focaliza su atención en el tercero. No obstante, la indistinción trae como consecuencia una serie de insuficiencias.

La primera de ellas apunta contra la asimetría total entre lengua y habla. A partir de la indistinción entre los tres conceptos de la lengua, Coseriu señala que la dicotomía saussureana padece de un defecto explicativo puesto que no logra dar cuenta de la transición o las gradas existentes entre la lengua y el habla. Para comprobar su punto de vista,

28. Cfr. COSERIU, Eugenio. "Sistema, norma y habla”. En: Teoría del Lenguaje y Lingüística General. Cinco estudios. $2^{\circ}$ ed. Madrid: Gredos, 1962/1969, p. 41.

29. Dice Coseriu: "En la doctrina de Saussure, ellos aparecen entremezclados; sus contornos no aparecen definidos ni se establecen las necesarias diferencias entre ellos; sin embargo, no se trata, según nosotros, de verdadera incoherencia, sino más bien de insuficiente desarrollo; no se trata de verdaderas definiciones, sino más bien de tentativas de caracterización de una intuición importante, pero todavía algo imprecisa”. COSERIU, Eugenio. "Sistema, norma y habla” ..., p. 47.

Revista de Ciencias Sociales - Número 67 (2015) - Universidad de Valparáíso - ISSN 0716-7725-Valparáiso, Chile 
aplica un esquema a partir del cual realiza distinciones en el lenguaje conformado por dos ejes: eje $\mathrm{A}=$ el punto de vista de la relación con el sujeto hablante arroja dos categorías: categoría 1) fenómenos referidos al sujeto; y categoría 2) fenómenos desligados del sujeto; y eje $\mathrm{B}=\mathrm{el}$ punto de vista del plano de abstracción considerado que deriva en dos grupos: categoría 1) fenómenos considerados en un grado inferior de formalización; y categoría 2) fenómenos considerados en un grado superior de abstracción.

La combinación de estos ejes arroja cuatro elementos: 1) la acción verbal, que es la acción de hablar en sí y en su momento de producción (individual y concreto), 2) el acto verbal, que es la atribución de una significación a un medio lingüístico (individual y formal), 3) el producto lingüístico, que resulta de la acción verbal considerado fuera de su producción y de su relación con las vivencias del individuo productor (interindividual y concreto); y 4) la forma lingüística, que es el mismo producto considerado abstractamente en su valor funcional y separado de las circunstancias de la situación verbal concreta (interindividual y formal).

El esquema se podría sintetizar de la siguiente forma ${ }^{30}$ :

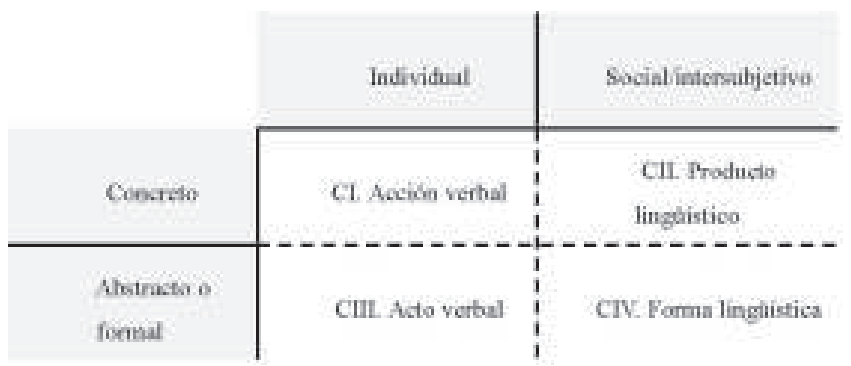

Para el lingüista rumano ${ }^{31}$ la insuficiencia en la teoría saussureana deviene de identificar el habla solo con el primer elemento,

30. Cuadro adaptado de la serie de esquemas presentados por Coseriu. En: Coseriu. "Sistema, norma y habla"..., pp. 48-51.

31. Aquí no se desarrollará el razonamiento completo de Coseriu debido a que no resulta necesario en relación con los objetivos de esta tesis, por lo que se remite a su obra para una profundización del tema. Al respecto, ver COSERIU. "Sistema, norma y habla"..., pp. 43-54.

Facultad de Derecho y Ciencias Sociales - Universidad de Valparaíso - Chile 
es decir, con la acción verbal (Cuadrante I), y la lengua con el cuarto elemento, o sea, la forma lingüística (Cuadrante IV) y no considerar los otros dos. La omisión de los elementos segundo y tercero es lo que lleva a no comprender correctamente la relación entre ambos extremos y a identificar lo concreto y asistemático con lo individual y lo formal y sistemático con social.

Por eso, si se afirma que es «lengua» lo que se considera desligado del sujeto, hay que admitir que el "producto lingüístico» es tan «extraindividual» como la «forma lingüística». (...) se manifiesta aquí un conflicto entre el punto de vista social y el punto de vista formal, pues si lo que es «social» es langue, entonces el «producto lingüístico» es parole, entonces ésta no se identifica con el aspecto exclusivamente individual del lenguaje. En efecto, la oposición entre «producto lingüístico»y «forma lingüística» no se basa en la antítesis individualsocial, sino en la antítesis asistemático-sistemático, concreto-abstracto ${ }^{32}$.

Si la lengua es lo formal, entonces incluye tanto la forma lingüística como el acto verbal, y si el habla es lo concreto entonces abarca la acción verbal y el producto lingüístico. Pero Saussure rechazaría la inclusión del acto verbal en la lengua por ser individual y no social, esto es, la lengua tiene que ser social y formal. También objetaría la inclusión del producto lingüístico en el habla por no ser individual, ergo, el habla es individual y concreta. Para sintetizar, Coseriu quiere mostrar que hay que desechar una de las dos opciones: a) la que contrapone concreto y abstracto, o b) la que identifica social y formal ${ }^{33}$.

Esta primera insuficiencia que Coseriu le atribuye a la concepción saussureana de la lengua a partir de las confusiones en la definición de esta, permite una reflexión en el ámbito del Derecho acerca de qué es el ordenamiento jurídico como sistema y qué son las decisiones judiciales. Si se tuviera que ubicar estos elementos en el cuadro anterior, se podría visualizar en forma gráfica la combinación de las categorías:

32. COSERIU, Eugenio. "Sistema, norma y habla”..., pp. 53-54.

33. Cfr. Ídem, pp. 46-55. 
social/individual y abstracto/concreto, con una comprensión más amplia que la mera oposición normas jurídicas y sistema normativo, por un lado, y las decisiones judiciales, por el otro.

\begin{tabular}{c|c|c|c}
\multicolumn{1}{c}{ Individual } & Social/intersubjetivo \\
\hline Concreto & CI. Decidir judicial & $\begin{array}{c}\text { CII. Ordenamiento jurídico } \\
\text { en cierto contexto }\end{array}$ \\
Abstracto/formal & CIII. Decisiones judiciales & $\begin{array}{c}\text { CIV. Ordenamiento } \\
\text { jurídico en cualquier } \\
\text { contexto }\end{array}$ \\
& & &
\end{tabular}

Esto revela que la supuesta dicotomía entre el ordenamiento jurídico y las normas jurídicas generales que lo constituyen, por un lado, y las decisiones judiciales, por el otro, no se construye sobre extremos radicalmente opuestos sino que existen grados de aproximación intermedios, por ejemplo, según el enfoque, la actividad decisora es tan individual como su producto, o sea, las decisiones judiciales, pero también es tan concreta como el ordenamiento jurídico en un determinado contexto. Asimismo, las decisiones judiciales pueden ser estudiadas a partir de cierto grado de abstracción al igual que los ordenamientos jurídicos en cualquier contexto, es decir, como pura forma jurídica. De esta manera, la oposición entre los pares individual/ social y concreto/abstracto no es de gran utilidad en el ámbito del Derecho si se olvida la gradualidad que une los extremos decisiones judiciales/ordenamiento jurídico. Así, al igual que ocurre en la Lingüística, en la órbita jurídica hay que descartar una de las asociaciones: lo social y formal o lo concreto y lo individual.

Una vez hecho esto, resulta más simple comprender que las decisiones judiciales influyen en el sentido general del ordenamiento jurídico. Por un lado, si son individuales lo es solo en relación con la instancia concreta de la decisión, porque proviene de un determinado juez, ante ciertas partes y en circunstancias tempo-espaciales particulares que la dotan de originalidad. Pero esta individualidad no obstaculiza la vocación de generalidad del decidir judicial puesto que su sentido puede ser pensado en abstracto o en un grado de formalización mayor.

Facultad de Derecho y Ciencias Sociales - Universidad de Valparaíso - Chile 
Es en esta instancia cuando se puede notar que ya no es un elemento inasible (como lo planteara Saussure en relación con el habla) sino un elemento que se integra al ordenamiento jurídico como un producto consolidado de este. Cuando, a su vez, se reflexiona sobre el impacto que aquella decisión judicial tiene sobre el sistema y el nuevo sentido que adquiere el conjunto, entonces, se puede comprender al ordenamiento jurídico en cierto contexto.

La segunda insuficiencia consiste en la no consideración del punto de encuentro entre lengua y habla. Coseriu sigue la línea del esquema presentado antes y señala que la dicotomía saussureana es demasiado rígida e ignora el punto en el que la lengua y el habla se encuentran y combinan. Este punto es el acto verbal (Cuadrante III) que es un hecho de la lengua y no debe ser confundido con la acción verbal (Cuadrante I). Esto le permite a Coseriu introducir la idea de que fuera del sujeto existen elementos que no son únicos u ocasionales sino sociales, normales y repetidos en el hablar de una comunidad (Cuadrante II) y que, sin embargo, no pertenecen al sistema funcional de las formas lingüísticas (Cuadrante IV) ${ }^{34}$.

En la órbita jurídica ocurre que si se considera a las decisiones judiciales como el punto de encuentro se puede entender que fuera de cada juez decisor existen elementos que no son absolutamente individuales, propios e irrepetibles sino que son sociales, que responden a una suerte de "polifonía" 35 , que ocurren de manera normal y que son repetidos en el obrar que se lleva a cabo en una comunidad por sus individuos y que, a pesar de ser elementos no totalmente individuales, no son exactamente formales o sistémicos.

Por último, la tercera insuficiencia radica en la concepción del individuo de Saussure. Coseriu también apunta que este es un sujeto

34. Cfr. Ídem, pp. 55-56

35. Se señala que esta idea es más bien una "suerte de polifonía” en tanto en la Lingüística esta idea funciona como una multiplicidad de voces, literalmente. En cambio, aquí, más bien se recurre a una metáfora de la polifonía para señalar que el ejemplo de otros reaparece en las acciones de sus pares, es decir, que las acciones humanas no son nunca puramente individuales sino que se inspiran en cierto marco social y político. Esto responde a la politicidad de la naturaleza humana.

Revista de Ciencias Sociales - Número 67 (2015) - Universidad de Valparáíso - ISSN 0716-7725-Valparáiso, Chile 
completamente separado de la sociedad y que no sería él mismo colectividad. En el habla no hay nada social. Si esto es así, por un lado, no tiene sentido la afirmación saussureana respecto de la interdependencia entre lengua y habla; por el otro, sería imposible que el individuo pudiera realizar el sistema social. Si no hay nada de social en el habla, la lengua no puede manifestarse en esta. Así, solo cabe decir que la distinción entre individual y social que hace Saussure es demasiado rígida. Esto da lugar a señalar que en los actos individuales se pueden comprobar dos formas del sistema: 1) la normal y 2) la funcional ${ }^{36}$.

Esta tercera insuficiencia apuntada por Coseriu, trasladada al campo del Derecho, conduce a señalar que los jueces no son sujetos aislados y contrapuestos a la comunidad por lo que sus decisiones no son individuales en el sentido de una pertenencia pura y exclusiva o de ser el producto de una invención netamente personal. Esto no permitiría comprender cabalmente la interdependencia entre las normas jurídicas y el ordenamiento que componen y las decisiones judiciales, esto es, no podría explicarse cómo el sistema jurídico, de características generales, se vincula con las decisiones que los jueces toman en los casos concretos a la luz de la normativa aplicable.

\section{La dialogicidad y la polifonía como características de las decisiones judiciales}

Bajtín ${ }^{37}$ concentra sus críticas al Curso de lingüistica general a partir de plantear el menosprecio del rol del oyente en el esquema comunicativo saussureano. El lingüista soviético apunta que, si bien no se lo puede calificar de falso, sí se puede decir que no responde a la totalidad del proceso dialógico. Por el contrario, solo representa un instante de la comunicación humana. El gran defecto que posee este

36. Cfr. Ídem, pp. 56-57.

37. Al respecto, para ampliar, ver BAJTíN, Mikel. Estética de la creación verbal. Tatiana Bubnova (trad.) $10^{\circ}$ ed. México/Madrid: Siglo XXI, 1982/1999. En especial, es relevante el apartado "El Enunciado como unidad de la comunicación discursiva. Diferencia entre esta unidad y las unidades de la lengua (palabra y oración)" incluido en el capítulo "El problema de los géneros discursivos".

Facultad de Derecho y Ciencias Sociales - Universidad de Valparaíso - Chile 
esquema es que se menosprecia el rol que tiene el oyente. El papel del otro ("otro" en relación con el hablante) solo se toma en cuenta como el del oyente pasivo, el del que comprende al hablante y es tan sólo un receptor del mensaje. Así, la lengua tan sólo requiere al hablante y si funciona como vehículo de comunicación es en forma accidental y accesoria. Lo que se olvida aquí, según Bajtín, es que toda comprensión apareja una respuesta por parte del oyente ${ }^{38}$

Esta réplica puede ser más o menos inmediata o su llegada puede dilatarse largamente en el tiempo pero tarde o temprano lo que se escucha de otros resurge en los discursos posteriores, de allí que existe una polifonía, una multiplicidad de voces.

En efecto, el oyente, al percibir y comprender el significado (lingüístico) del discurso; simultáneamente toma con respecto a éste una activa postura de respuesta: está o no está de acuerdo con el discurso (total o parcialmente), lo completa, lo aplica, se prepara para una acción, etc.; y la postura de respuesta del oyente está en formación a lo largo de todo el proceso de audición y comprensión desde el principio, a veces, a partir de las primeras palabras del hablante ${ }^{39}$.

La comprensión que efectúa el oyente y la respuesta que en él se gesta implican una etapa también activa del diálogo. De allí el repudio a la calificación como de meramente pasiva que se le atribuye en el

38. Coseriu menciona que Vossler insistía también en la importancia de un factor ignorado hasta su época: el oyente. Dado que la finalidad del acto lingüístico es comunicar algo a alguien no se puede soslayar la necesidad de contar con al menos dos individuos que formen parte del diálogo. Esta idea puede ser consultada en VOSSLER, Karl. Positivismus und Idealismus in der Sprachwissenschaft. Eine sprachphilosophische Untersuchung. Heidelberg: Karl Winter's Universitätsbuchhandlung, 1904. También se ha utilizado la versión italiana: VOSSLER, Karl. Positivismo e Idealismo nella Scienza del Linguaggio. Gnoli, 1094.

Para Coseriu, en contraposición con Saussure, justamente, el acto lingüístico no pertenece sólo a un individuo sino que este es al mismo tiempo individual y social. Cfr. COSERIU, Eugenio. Introducción a la lingüística. Madrid: Ed. Gredos, 1986, pp. 30-31.

39. BAJTÍN. Op. Cit., p. 257.

Revista de Ciencias Sociales - Número 67 (2015) - Universidad de Valparáíso - ISSN 0716-7725-Valparaíso, Chile 
esquema saussureano. Para Bajtín, este oyente no es real sino completamente ficticio. Por un lado, Saussure no aclara que el momento descrito en el esquema dialógico sea tan sólo un instante del proceso total pero tampoco se desarrolla ni se completa el resto del proceso de manera de indicar la relevancia que tiene el receptor en él.

Aún más, el hablante mismo cuenta con una comprensión activa y productora de respuesta. Difícilmente un emisor solo espere de su interlocutor que únicamente reproduzca una idea en su cabeza. Quien habla espera una contestación, una participación, consentimiento, asentimiento, objeción, acatamiento de una orden, etc. ${ }^{40}$.

Un esquema semejante al saussureano aplicado al Derecho, es decir, que contemple normas jurídicas generales y al ordenamiento jurídico que estas conforman, dirigidas a los sujetos normativos que las receptan de manera pasiva, también es insuficiente y parcial. Los receptores realizan una interpretación de los enunciados normativos que, relacionados, regulan un caso concreto, lo comprenden conforme a sus circunstancias y a su contexto y no conforme exactamente lo tuvo en cuenta la autoridad normativa. De esta manera, existen tantos sentidos de las normas jurídicas generales y del ordenamiento jurídico que ellas conforman como decisiones judiciales se deban tomar.

Por otro lado, paulatinamente, el conjunto de los actos hermenéuticos de los individuos labran modificaciones en el sistema. El sentido de las normas jurídicas generales no se auto-determina sino que se define a partir de las interpretaciones que realizan los jueces y que son volcadas en sus decisiones, esto es, de cómo actúan y ponen en funcionamiento el ordenamiento jurídico a la luz de un caso concreto. Así, las sentencias se inspiran unas a otras. El concepto de polifonía bajtiniana es aplicable a las decisiones judiciales: los precedentes, lo que otros han decidido, lo que otros han interpretado e incluso lo que

40. Cfr. Ídem, p. 258. En la misma sintonía, Kerbrat-Orecchioni plantea una serie de reformulaciones al esquema comunicativo de Jakobson a fin de resaltar la complejidad del hecho comunicacional en relación con los factores del circuito. Así, agrega distintas competencias, restricciones y determinaciones que ponen en relieve la complejidad de las instancias emisora y receptora. Al respecto ver KERBRATORECCHIONI, Catherine. La enunciación. De la subjetividad en el lenguaje. Gladys Anfora y Emma Gregores (trad.). $2^{\circ}$ ed. Buenos Aires: Edicial, 1993.

Facultad de Derecho y Ciencias Sociales - Universidad de Valparaíso - Chile 
la autoridad normativa ha tenido en mente regular, también reaparece en nuevos productos hermenéuticos que realizan un reparto jurídico.

\section{La carga activa entre todos los sujetos actuantes}

En otros términos, también a partir de los postulados bajtinianos, se critica el olvido de la importancia de la expresión y de la delimitación de los enunciados por parte de los sujetos hablantes en el esquema comunicativo de Saussure. El discurso existe en la realidad a través de

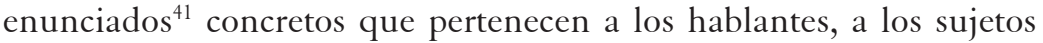
discursivos, ya que estos son quienes delimitan sus fronteras. Esta idea remite a otras dos vinculadas a: 1) la relevancia de la expresión para la lengua y 2) el concepto (o, más bien, los conceptos) de alteridad.

De acuerdo a 1), Bajtín dice que las palabras de la lengua no son de nadie. Sin embargo, al mismo tiempo, solo las oímos en enunciados individuales en los cuales no sólo aparece un matiz típico sino también una expresividad individual fijada en el contexto particular e irrepetible ${ }^{42}$.

En cuanto a 2), en el diálogo, el punto final de un enunciado llega cuando cambia el sujeto hablante. En este sentido, puede notarse que la alteridad se presenta en la postura de este autor de dos maneras: una primera, en la necesidad de la existencia de dos sujetos dialogantes y que implica los roles de sujeto hablante y sujeto oyente (con la carga activa que ambos implican), y, una segunda, en la alternancia que se produce en el diálogo puesto que a cada enunciado le correspondería su réplica.

41. Para Bajtín, los enunciados son el objeto del discurso ya que tienen fronteras. Estas fronteras radican en la alternación de los hablantes, es decir, un enunciado concluye cuando el sujeto hablante calla y le cede el turno a su interlocutor. Además, la conclusión del enunciado está signada por la comprensibilidad del contenido y la intención de este. Ello, en contraposición con los elementos de la lengua (las palabras y las oraciones) que son impersonales, que no son enunciadas por nadie ni para nadie. Su completitud - y en especial la de las oraciones- no se haya sino en el marco de un enunciado discursivo.

42. Cfr. BAJTÍN, Op. Cit., p. 278.

Revista de Ciencias Sociales - Número 67 (2015) - Universidad de Valparáíso - ISSN 0716-7725-Valparaíso, Chile 
Así como la realidad concreta del discurso es su enunciación por parte de los sujetos, el orden del reparto abstracto que prescribe el sistema de normas jurídicas generales también cobra sentido a partir de su aplicación concreta, es decir, gracias a ser repartos de bienes determinados entre partes también individualizadas. Esto deriva en que el reparto jurídico, en abstracto, en realidad no le pertenezca a ningún sujeto en particular, las cosas a las que se refieren las normas jurídicas generales son conceptos genéricos, pero esta situación cambia cuando un juez decide qué le es debido a quién y quién es el sujeto deudor. Estas decisiones son únicas e irrepetibles porque se caracterizan por las notas de cada caso en particular, aun cuando sean inspiradas por las normas jurídicas generales como pautas del reparto.

En cuanto a la dialogicidad como aporte, esta se ve en dos instancias. La primera de ellas se da en la misma naturaleza de las normas jurídicas generales que son mensajes a ser comunicados a los sujetos normativos y a los jueces que deben aplicarlas. La segunda ocurre en las decisiones judiciales que deben necesariamente ser comunicadas a las partes involucradas como destinatarios directos y a los miembros de la comunidad y a otros jueces como destinatarios indirectos ${ }^{43}$. En ambos casos, los receptores interpretan los mensajes y al hacer esto, en forma activa (y no meramente pasiva), al desentrañar el mensaje, modifican levemente el significado, lo completan, lo comparan con experiencias anteriores, se preparan para actuar en conformidad o no con él, etcétera.

El destinatario de la norma jurídica es también un actor activo — valga la redundancia - y relevante en el proceso de normatividad. Es quien comprende y actúa en consecuencia. El receptor es un hermeneuta que desarrolla una labor de desentrañamiento activa que va más allá de los datos del mensaje y que contempla su propio contexto, sus propias vivencias, su proceso intelectual y voluntad.

43. Indirectamente, estas decisiones judiciales también se dirigen al resto de la comunidad jurídica y a otros jueces, en especial, a los de superior jerarquía puesto que poseen una pretensión secundaria (la primaria es la de convencer y persuadir a las partes) de convencer respecto de los argumentos allí vertidos para que no sean revocadas.

Facultad de Derecho y Ciencias Sociales - Universidad de Valparaíso - Chile 
Además claramente el emisor espera de sus interlocutores una respuesta: en el caso de las normas jurídicas generales, o bien de adecuación a la norma o no; en este último caso, con las consecuencias jurídicas pertinentes. En el caso de las decisiones judiciales, en relación con las partes, los jueces en sus decisiones vuelcan argumentos a fin de lograr que los destinatarios las acaten y, mediatamente, para que, en caso de que se plantee un recurso, estas no sean revocadas.

\section{Consideraciones finales}

A partir de las críticas enunciadas anteriormente, cabe efectuar al menos tres reformulaciones en las consideraciones a la mirada "saussureana" respecto del Derecho.

- Primera reformulación: se deben considerar diferentes niveles de abstracción y concreción entre el sistema y los actos individuales.

De acuerdo con lo que se ha explicado en las críticas antes expuestas, la separación entre el sistema y los actos individuales - tanto en el modelo saussureano para la Lingüística, respecto de la lengua y el habla, como en su paralelo en el campo jurídico, en relación con el ordenamiento jurídico y las decisiones judiciales - reviste características antinómicas e irreconciliables. A pesar de reconocerse cierta interdependencia entre los extremos, en aquel primer modelo, estos elementos se plantean como separados y propios de estudio de diferentes disciplinas. Como se ha visto en las críticas, este abismo expuesto con excesiva rigidez, debe reconocer algunas flexibilizaciones. De hecho, el grado de rigidez/flexibilidad con que se aborde la pretendida dicotomía depende de la mirada del investigador y no del objeto en sí mismo. Por ello, para dar cuenta de la complejidad del Derecho articulado en dos analogados normativos es necesario exponer la relación que existe entre el ordenamiento jurídico y las decisiones judiciales, sin colocarlos como dos extremos dicotómicos sino, más bien, que gradualmente se acercan entre sí.

Para poder analizar estos niveles entre lo abstracto y lo concreto entre los analogados mencionados, se debe partir, conforme a una visión realista, del decidir judicial como actividad repartidora concreta. A partir

Revista de Ciencias Sociales - Número 67 (2015) - Universidad de Valparáíso - ISSN 0716-7725-Valparaíso, Chile 
de ello, es posible conceptualizar con mayor grado de abstracción los diferentes niveles que sirven de punto de encuentro entre los extremos al considerar los diferentes productos de dicha actividad.

Como se ha señalado, es posible reconocer cuatro elementos distintos en la consideración de diferentes grados que oscilan entre lo abstracto y lo concreto, combinado con lo social y lo individual. En relación con las decisiones judiciales, estas constituyen un grado mayor de formalización que el decidir judicial y constituyen un primer producto de esta actividad. Ambos son realidades individuales. Por otro lado, se puede considerar dos grados del ordenamiento jurídico como realidad de carácter social o intersubjetivo. El más concreto de ellos es el que se ha denominado "ordenamiento jurídico en cierto contexto", es decir, el sentido concreto que el sistema posee en determinado tiempo y lugar, el conjunto de decisiones judiciales actuales y los motivos por los cuales se generan nuevos criterios hermenéuticos y aquellos por los cuales otras interpretaciones son dejadas de lado. Es el campo semántico del sistema contextualizado. En cambio, el grado de mayor abstracción lo constituye el que anteriormente se ha llamado "ordenamiento jurídico en cualquier contexto", esto es, como forma, como un sistema de posibilidades acerca de lo que puede y no puede decirse respecto de las normas jurídicas. De cierta manera, marca el camino entre aquello que escapa claramente al campo semántico amplio de las prescripciones pero también brinda un vasto margen respecto de las posibilidades interpretativas.

Por su parte, el decidir judicial es una actividad que se desenvuelve dentro de aquel marco de posibilidades formales y de las interpretaciones usuales, lo cual hace a sus productos comprensibles y aceptables. Las decisiones judiciales son siempre creativas y singulares puesto que instauran repartos concretos entre sujetos determinados y son enunciadas por un juez en circunstancias determinadas. Así, se constituyen en una expresión inédita que concreta al ordenamiento jurídico frente a un caso particular.

Por otro lado, si bien importan un nuevo acto con un sentido jurídico que puede ser novedoso, las decisiones judiciales implican una reconstrucción del sentido del ordenamiento jurídico en ciertas circunstancias. A su vez, estos nuevos actos individuales se inspiran en

Facultad de Derecho y Ciencias Sociales - Universidad de Valparaíso - Chile 
otros anteriores porque deben ser comunicados a otros sujetos: las partes, otros jueces, los operadores jurídicos, la comunidad jurídica en general, entre otros. Por ello, se puede afirmar, de manera análoga a lo que señala $\mathrm{Coseriu}^{44}$, que no se aprende un ordenamiento jurídico, sino a crear en el marco del ordenamiento jurídico.

Finalmente, cabe destacar que la existencia de las formulaciones de las normas jurídicas y de su sentido genérico y genético es innegable, pero puede apreciarse que, a pesar de su existencia real, el reparto que ellas instauran es hipotético y así permanece. No obstante su sentido general es comprendido aunque parte de su vitalidad se pierde al no concretarse en la atribución del suyo de alguien y debido a otro. Tras el nacimiento de una norma poco se conoce sobre ella y cuanto más hayan dicho los jueces acerca de su sentido en sus sentencias, más se sabe acerca de su significado ${ }^{45}$.

- Segunda reformulación: las decisiones judiciales son actos individuales pero sociales al mismo tiempo.

Esta reformulación se basa en aquellas afirmaciones saussureanas que señalan que el sistema, por un lado, posee naturaleza social y pertenece a la faz pasiva y los actos individuales, por el otro, son esencialmente particulares y asociales y pertenecen a la faz activa (en el caso de la Lingüística, la lengua se ubica en el primer extremo y el habla en el segundo, mientras que, en la visión paralela del Derecho, el ordenamiento jurídico posee las primeras características y las decisiones judiciales, las segundas). Asimismo, se sustenta en las críticas que

44. Dice este lingüista que, en realidad, no se aprende una lengua sino que se aprende a crear en una lengua, se aprenden las normas que guían la creación en una lengua, las directivas y los elementos que el sistema proporciona como moldes para la expresión inédita. Cfr. COSERIU, Eugenio. "Sistema, norma y habla"..., pp. 99-100.

45. Cfr. VIGO, Rodolfo Luis. Exposición oral en el marco de la conferencia inaugural de las Jornadas Regionales de Derecho Judicial del Foro Patagónico de Superiores Tribunales de Justicia: "La ciencia y la tecnología al servicio de la Magistratura y el Derecho Judicial”, organizadas por el Foro Patagónico de Superiores Tribunales de Justicia, el Poder Judicial de la Provincia de La Pampa y la Universidad Austral. Realizadas en Santa Rosa, La Pampa. 20 de septiembre de 2011.

Revista de Ciencias Sociales - Número 67 (2015) - Universidad de Valparáíso - ISSN 0716-7725-Valparáíso, Chile 
señalan que el primer modelo 1) no tiene en cuenta los efectos de los actos de los otros sujetos y su reaparición en los actos individuales, 2) que no considera la carga activa que se da entre todos los sujetos actuantes y 3) confunde diferentes acepciones del sistema.

En este marco, las decisiones judiciales constituyen productos de la actividad decisora judicial y, por lo tanto, pertenecen al plano individual y poseen un grado de abstracción mayor que el decidir judicial. Esta formalización distingue la actividad mientras ocurre, fenómeno inasible en términos saussureanos, de un acto individual tomado en abstracción de la ejecución misma.

La característica de la individualidad de las decisiones judiciales si bien se relaciona con el hecho de ser enunciadas por un juez, frente a determinadas partes, y ante cierto caso concreto, no se refiere a la pertenencia exclusiva a un individuo o a la particularidad de las circunstancias. Más bien, se debe entender la individualidad como la originalidad y la unicidad correspondientes a las decisiones judiciales puesto que estas son intuiciones inéditas del ordenamiento jurídico frente a ciertos hechos. Nunca son iguales entre sí, ni siquiera en el mismo sujeto decisor o ante las mismas partes.

Las decisiones judiciales se caracterizan por la creatividad por la cual crean repartos únicos y singulares. No obstante, esta creatividad encuentra ciertos límites: por un lado, se debe tener en cuenta el rango de posibilidades interpretativas que habilita el ordenamiento jurídico como forma, es decir, en el grado más abstracto, y, por el otro, se debe considerar el conjunto de interpretaciones ya efectuadas y actuales del sistema, es decir, el ordenamiento jurídico en las circunstancias hermenéuticas. Estos límites a la libertad decisora se imponen a efectos de lograr que las normas tengan medianamente el mismo sentido y que las decisiones judiciales sean comprensibles y aceptables ${ }^{46}$.

A la luz de lo dicho, si bien las decisiones judiciales son individuales por su naturaleza, se encuentran socialmente vinculadas por su

46. Por otro lado, cabe destacar que dos principios fundamentales en todo Estado de Derecho son la igualdad formal ante la ley y la seguridad jurídica, lo cual requiere necesariamente que exista un rango de interpretaciones válidas y otras que no puedan ser consideradas como propias de las normas.

Facultad de Derecho y Ciencias Sociales - Universidad de Valparaíso - Chile 
finalidad. Esta característica de ser sociales deviene de dos instancias: 1) por la dialogicidad necesaria y propia de las sentencias, y 2) por la polifonía que ellas encierran. La primera, en cuanto que implica que las decisiones judiciales sean comunicadas a las partes, como auditorio directo, y a otros jueces y la comunidad jurídica en general, como auditorio indirecto. Por lo tanto, para ser comunicadas deben poseer algún parámetro de entendimiento en común con los destinatarios, de los cuales se espera que comprendan el mensaje, lo compartan y lo acaten. Incluso, en el caso de otros jueces, que acepten el sentido propuesto y lo apliquen en sus propias decisiones futuras. La segunda, porque cada decisión no es innovación pura sino reconstrucción del sistema, retoma lo ya interpretado, descarta ciertos criterios, reafirma otros, crea algo nuevo pero aceptable dentro del campo semántico contextualizado del ordenamiento jurídico. Esta polifonía hace referencia al vínculo con lo ya interpretado por otros, a aquello que es compartido con otros, a lo que los demás han dicho/dicen y que resurge en las nuevas decisiones.

- Tercera reformulación: las decisiones judiciales no son sólo actos de creación sino que también son de recreación de actos individuales anteriores.

En los acápites anteriores se ha mencionado que las decisiones judiciales no son sólo actos de creación y pura innovación, sino que son, por sobre todo, actos de recreación de actos individuales anteriores que, por haber sido adoptados, se han difundido y forman parte del ordenamiento jurídico en ciertas circunstancias. A este fenómeno, se lo ha caracterizado como una suerte de paralelo a la polifonía bajtiniana expuesta en las críticas al modelo saussureano puesto que se lo considera útil para representar la idea de la multiplicidad de voces, de interpretaciones o de otros actos individuales que sirven como insumo para la toma de nuevas decisiones.

Conforme a lo dicho, las decisiones judiciales, son actos creativos en tanto instauran nuevos repartos, pero no todo en ellas es completamente novedoso sino que también implican un recurso a lo que radica en la memoria del sujeto decisor, embebido de su propio horizonte hermenéutico. Así, el juez no puede abstraerse completamente de las interpretaciones usuales del ordenamiento jurídico en cierto momento y de aquello que es correcto.

Revista de Ciencias Sociales - Número 67 (2015) - Universidad de Valparáíso - ISSN 0716-7725-Valparaíso, Chile 
Las sentencias no son meras copias de las normas jurídicas generales sino que, dentro del marco que ellas ofrecen, poseen una porción de invención personal dentro de ciertos límites. Pero no toda innovación se consagra como un sentido asociado de las formulaciones normativas sino que, para ello, se requiere la aceptación y difusión de la interpretación, es decir, de su adopción, instancia en la cual, pasa a formar parte del ordenamiento jurídico en cierto contexto.

La cuota de recreación de las decisiones judiciales se da porque estas se nutren del estado hermenéutico anterior y se valen de este como insumos para el establecimiento de un nuevo reparto, comunicable y compartible con los destinatarios. Los jueces, al sentenciar, no sólo se valen del sistema en abstracto, esto es, de los caminos hermenéuticos abiertos y cerrados sino también de cómo este ha sido puesto en práctica y cómo se lo ha interpretado y se lo interpreta.

\section{BIBLIOGRAFÍA CITADA}

ALCHOURRÓN, Carlos E. y BULYGIN, Eugenio. Introducción a la metodología de las ciencias jurídicas y sociales. $2^{\circ}$ reimpresión.

Buenos Aires: Astrea, 1975/1993.

ALEXY, Robert. El concepto y la naturaleza del derecho. Carlos Bernal Pulido (trad.). Madrid/Barcelona/Buenos Aires: Marcial Pons, 2008.

ÁLVAREZ GARDIOL, Ariel. Manual de filosofía del derecho. Buenos Aires: Editorial Astrea, 1979.

BAJTÍN, Mikel. Estética de la creación verbal. Tatiana Bubnova (trad.) $10^{\circ}$ ed. México/Madrid: Siglo XXI, 1982/1999.

BARBERIS, Mauro. "Estructura y dinámica de los sistemas jurídicos". Doxa. Cuadernos de Filosofía del Derecho. N$^{\circ}$ 20, 1997. Alicante: Universidad de Alicante.

BERNAL, Carlos L. "Un análisis de las decisiones judiciales con base en la teoría de los actos de habla". European Journal of legal studies.

Autumn/Winter. 2007. Volume 1. Issue 2.

BULYGIN, Eugenio. "Sentencia judicial y creación de derecho”. En: Alchourrón, Carlos y Bulygin, Eugenio. Análisis lógico y Derecho.

Madrid: Centro de Estudios Constitucionales, 1992.

Facultad de Derecho y Ciencias Sociales - Universidad de Valparaíso - Chile 
Ordenamiento jurídico y decisiones judiciales: aproximaciones...

COSERIU, Eugenio. "Sistema, norma y habla". En: Teoría del Lenguaje

y Lingüística General. Cinco estudios. $2^{\circ}$ ed. Madrid: Gredos, 1962/ 1969.

COSERIU, Eugenio. Introducción a la lingüística. Madrid: Ed. Gredos, 1986.

CUETO RÚA, Julio César. "La jurisprudencia sociológica norteamericana”. En: Anuario de filosofía jurídica y social. Buenos Aires: Asociación Argentina de Derecho Comparado. Abeledo Perrot, 1981, pp. 59-73.

DE GIORGI, Raffaele. Ciencia del Derecho y legitimación. México: Universidad Iberoamericana, 1998.

DOUGLAS PRICE, Jorge Eduardo. "¿Qué sistema? La idea de "sistema jurídico" y una "confusión" epistemológica”. Ideas \& Derecho. $N^{\circ}$ 8, año 2012. Buenos Aires: Asociación Argentina de Filosofía del Derecho, pp. 53-74.

DOUGLAS PRICE, Jorge Eduardo. La decisión judicial. Santa Fe: Rubinzal-Culzoni, 2012.

GARCÍA MÁYNEZ, Eduardo. Introducción al Estudio del Derecho. $51^{\circ}$ ed. México: Ed. Porrúa.

HERNÁNDEZ GIL, Antonio, NÚÑEZ LADEVÉZE, Luis, SOBRADO CHÁVEZ, Juan José, MESA MENGÍBAR, Andrés, PECES Y MORATE, Jesús Ernesto y PÉREZ DE GRACIA, José Antonio. Estructuralismo y Derecho. Madrid: Editorial Alianza, 1973.

HERNÁNDEZ MARÍN, Rafael. Introducción a la teoría de la norma jurídica. Madrid: Marcial Pons, 1998.

KERBRAT-ORECCHIONI, Catherine. La enunciación. De la subjetividad en el lenguaje. Gladys Anfora y Emma Gregores (trad.). $2^{\circ}$ ed. Buenos Aires: Edicial, 1993.

LELL, Helga María. "Hermenéutica judicial y discurso judicial: la retórica como instrumento para la aceptación de sentidos normativos novedosos". Ponencia expuesta en el II Coloquio Nacional de Retórica "Los códigos persuasivos: historia y presente" y el I Congreso Internacional de Retórica e Interdisciplina, organizado por la Asociación Argentina de Retórica (AAR) y llevado a cabo en Mendoza, Argentina, los días 21, 22 y 23 de marzo de 2013.

LELL, Helga María. "La Equidad: un criterio de interpretación legal”. Trabajo presentado en la mesa redonda de Ciencias Jurídicas: "A

Revista de Ciencias Sociales - Número 67 (2015) - Universidad de Valparáíso - ISSN 0716-7725-Valparáiso, Chile 
Antiguidade no Direito" en el XVIII Congresso Nacional de Estudos Clássicos. Antiguidade: Performance e Recepção, llevado a cabo en la Universidad Federal de Río de Janeiro con el auspicio de la Sociedad Brasilera de Estudios Clásicos, en Río de Janeiro, Brasil, los días 17 al 21 de octubre de 2011.

LUHMANN, Niklas. Sistema jurídico y dogmática jurídica. Madrid: Centro de Estudios Constitucionales, 1983.

MASSINI CORREAS, Carlos Ignacio. El derecho natural y sus dimensiones actuales. Buenos Aires: Editorial Ábaco, 1999.

MORESO, Juan José y VILAJOSANA, Josep María. Introducción a la teoría del derecho. Madrid: Marcial Pons, 2004.

SAUSSURE, Ferdinand de. Cours de linguistique générale. Publié par Charles Bally et Albert Séchehaye avec la collaboration de Albert

Riedlinger. Édition critique préparée par Tulio de Mauro. Paris : Éditions Payot \& Rivages, 1967.

SAUSSURE, Ferdinand de. Curso de lingüística general. Publicado por Charles Bally y Albert Sechehaye con la colaboración de Albert Riedlinger. Amado Alonso (trad.). Buenos Aires: Losada, 1945.

VIGO, Rodolfo Luis. Exposición oral en el marco de la conferencia inaugural de las Jornadas Regionales de Derecho Judicial del Foro Patagónico de Superiores Tribunales de Justicia: "La ciencia y la tecnología al servicio de la Magistratura y el Derecho Judicial”, organizadas por el Foro Patagónico de Superiores Tribunales de Justicia, el Poder Judicial de la Provincia de La Pampa y la Universidad Austral. Realizadas en Santa Rosa, La Pampa. 20 de septiembre de 2011.

VITALE, Alejandra. El estudio de los signos. Peirce y Saussure. $1^{\circ}$ ed. $9^{\circ}$ reimp. Buenos, Aires: Eudeba, 2010.

VOSSLER, Karl. Positivismo e Idealismo nella Scienza del Linguaggio. Gnoli, 1094.

VOSSLER, Karl. Positivismus und Idealismus in der Sprachwissenschaft. Eine sprach-philosophische Untersuchung. Heidelberg: Karl Winter's Universitätsbuchhandlung, 1904.

WITTGENSTEIN, Ludwig. Tractatus lógico-philosophicus. Edición bilingüe. Jacobo Muñoz e Isidora Reguera (trad.). $1^{\circ}$ ed. $4^{\circ}$ reimp. Madrid: Alianza Ed., 1987/1993.

Facultad de Derecho y Ciencias Sociales - Universidad de Valparaíso - Chile 